\title{
Blogging politics in Cuba: The Framing of Political Discourse in the Cuban Blogosphere
} \author{
socialist rhetoric among state-aligned bloggers. \\ Dr. Stefania Vicari \\ Department of Media \& Communication, \\ University of Leicester \\ Bankfield House, 132 New Walk \\ Leicester . LE1 7JA . UK \\ E.sv32@le.ac.uk \\ T. +44 (0)1162231616
}

Abstract. While a growing literature is exploring blogs and blogospheres as loci for informal political engagement, the development of political discourse via specific framing dynamics in blogging practice has so far been overlooked. By investigating the content of 62 blogs from four different ideological streams, this study specifically focuses on the Cuban blogosphere to address the question of how political consciousness and potential for collective action may emerge in blogging practice. Findings show that 1) critical evaluations, personal narratives and traditional socialist rhetoric mix as the raw materials of an emerging online political debate; 2) this particular mix varies depending on the political leaning of the bloggers; 3 ) potential for collective action is very limited mostly due to the lack of a strong agency component among critical bloggers and the still heavy presence of an outdated

Blogging is becoming a topical object of investigation for studies interested in the emergence of political discourse in non-traditional platforms of interaction and political engagement. In particular, blogosphere research has started looking at blogs as nodes of discourse networks, with blogging generating specific discourse patterns. Early research has primarily focused on the intertwining of public and private dimensions of discourse practices (Papacharissi, 2008) and the extent to which bloggers engage in reciprocal and constructive interactions (Adamic and Glance, 2005; Herring et al., 2005). Recent analyses of blogospheres in democratic contexts have shown that linking practices often reproduce specific cultural values (Moe, 2011; Park and Kluver, 2009) and that structural changes may affect network interactions (Chang Woo-young and Park, 2012). Case studies of blogospheres in authoritarian regimes show that there is often an interaction between local and transnational blogospheres (Chowdhury, 2008); blogospheres, although often fragmented, can provide access to alternative news and space for dissent (Radsch, 2008; Rahimi, 2011); and there is a level of variability in the way in which blog discourse practices are embedded in political contexts (Etling et al., 2010).

This article aims to address a question that has so far been overlooked, that is, how political consciousness emerges in blogging practice. By focusing on the Cuban context, the study explores the way in which, within a blogosphere's different ideological streams, political discourse unfolds via the development of specific framing dynamics. Cuba, despite having received little attention from blogosphere research in authoritarian regimes, makes an interesting case study for both its geopolitical background and Internet history. 
In the following sections, the paper will discuss theoretical contributions on political discourse and political cognition, with a specific focus on the use of frame theory in the analysis of political consciousness and cognitive potential for collective action. Next, data and methods will be described. The remainder of the paper will specifically develop a frame analysis of meaning construction in the Cuban blogosphere.

\section{Political discourse in everyday life}

The first question to be addressed in the analysis of political discourse concerns exactly the definition of "political", or which texts can be identified as political. Van Dijk (1995) suggests that political texts may be identified by looking at their wider context, that is, their actors, practices, elements of time and space, and other circumstantial attributes. If we aim to analyze a call for protest as an example of political discourse, for instance, we need to identify authors and audiences, explore dissent practices - e.g., in terms of claims, protest activities and forms of protest -, and consider the specific timing and location of both the call and the protest.

Given specific contextual characteristics, political discourse is often identified and measured on the basis of its potential to influence the institutional polity, or the ability to accomplish political aims and goals (Van Dijk, 1997: 14). While discussing the definition of "political discourse analysis," Fairclough and Fairclough (2012), for instance, discuss the application of an analysis of "practical argumentation," or argumentation that is deliberate over specific alternatives of action for or against institutional political choices. They state: "This is a view of politics in which the question of action, of what to do, is the fundamental question" (2012: 17, italics in the original). Hence, this view of politics also implies agency in the short-term, or the ability to engage in action aimed at quick political change.

Nevertheless, not always discourse, especially when pertaining to the nonofficial political domain, can influence directly political decision-making. If we look at the social movement literature, for instance, we realize that social movements, albeit functioning as collective social agents, in the short-to-medium term have often led to socio-cultural shifts rather than direct political changes (see, among the others, Giugni, 1998; 2012; Meyer and Whittier, 1994; Rochon, 1994). Giugni suggests that the major influence of social movements "resides not so much in provoking some immediate reaction from political leaders apart from increased repression, but in providing a fertile ground for what would come later. [...] This does not mean that the political impact of the movements is nonexistent, but that it is at best an indirect one." (2012: online). More so, if we draw our attention to everyday life texts, how do we ascertain if discourse is indicating an even indirect political change in the wider society?

This question may be addressed by looking at political contexts as characterized by a set of properties - general and specific -, as shown in Table 1.

\begin{tabular}{|lllll|}
\hline Societal domain $\rightarrow$ & Systems $\rightarrow$ & Values $\rightarrow$ & Ideologies $\rightarrow$ & Institutions $\rightarrow$ \\
\hline Organizations $\rightarrow$ & Groups $\rightarrow$ & Actors $\rightarrow$ & Relations $\rightarrow$ & Process $\rightarrow$ \\
\hline Actions $\rightarrow$ & Discourses $\rightarrow$ & Cognition & & \\
\hline
\end{tabular}

Table 1: Relevant categories for the definition of political context, from general to specific (Van Dijk, 1997: 16-18). 
If we look at the abstract domain of politics, we can interpret it as embodied by different political systems (e.g., dictatorship, democracy) and supported by political values (e.g., equality, freedom) that generate from specific ideologies (e.g., communism, fascism). Institutions, organizations, societal groups and actors then concretely support or dissent from those political systems. At different levels of this layered definition of political context, we find different relations between actors and entities (institutional or not) that lead to a fluid organization of the domain via the political process. The political process itself originates from specific political actions (e.g., governmental decisions, strikes). At the core of such political actions, we find political discourse that emerges from a shared definition of society as a working system, that is, from political cognition. In fact, political cognition - via animating perceptions, prejudices, and representations of public life - provides the symbolic grounds for political discourse.

Now, everyday life discourse may be politically contextualized in terms of its actors (i.e., authors and recipients) and practices (e.g., conversation, quarrel, written exchange). Further circumstantial indicators (e.g., time, place) may also be easily identified. But, most importantly, while in most cases its direct or indirect political impact could not be measured, one could investigate its "symbolic economy," (Van Dijk 1995: 44) that is, uncover processes of meaning construction around social power and power relations in society.

\subsection{Political Cognition and Frames}

Political cognition refers to the acquisition and elaboration of political knowledge, that is, of the narrative, descriptive and evaluative statements (Halliday and Matthiessen 2004) that we use for the construction of interpretative schemata of events, actors and groups having to do with the political domain. Van Dijk (2002) suggests that there is a direct relationship between political cognition and political discourse; a relationship where personal beliefs and attitudes mingle with more socially shared interpretative schemata. In fact, discourses may present socially shared beliefs and/or prejudices (e.g., conservative attitudes towards immigrants, liberalist approaches to economic crisis) but they also signal personalized, subjective mental models of political contexts. More specifically, Van Dijk (2002: 224) recognizes three dimensions of cognition in a cultural community: a general common sense knowledge, shared by the whole cultural community and mainly undisputed; a group knowledge, shared by the members of a specific group and coupled with that group's ideology; a personal knowledge developed at individual level and influenced by both common sense knowledge and group knowledge.

In the shift from political cognition to political discourse, knowledge items are organized in interpretative schemata, that is, they take specific order, prominence and direction within an organic structure of meaning. In the symbolic interactionist and constructionist traditions, the concept of interpretative schemata has been directly associated to that of frames. In fact, drawing upon Bateson's early work (1972) on human cognitive behaviour, Goffman explained frames as "schemata of interpretation" (1974: 21), or processes of signification where meanings become functional to organize social experience. After these early conceptualizations, different disciplines have provided their own elaborations of frame approaches (author removed: unpublished) but in this study we will specifically focus on frames in the domain of political cognition and political discourse.

In the specific domain of political cognition and political discourse, for the 
past thirty years the work of Snow, Benford and colleagues has become particularly prominent in redrawing academic attention to the interpretative dimension of mobilization, that centred on beliefs, values, and ideology (see, among the others, Benford, 1993a, 1993b, 1997; Benford and Snow, 2000; Snow 2004; Snow and Benford, 1988, 1992; Snow and Byrd 2007; Snow et al., 1986, 2007). But it was Gamson (1992a)'s work Talking Politics that pivotally investigated frames in everyday life discourse.

Gamson (1992a) describes frames as collective ideas, not necessarily used to engage in direct political action - as, for instance, in social movements claims - but functional to organize political consciousness that may later lead to mobilization. More specifically, Gamson looked at the way people discuss societal problems in everyday life, showing that in many cases "their conversation is divorced from an action context [...]; nevertheless, their frame has important collective action components" (1992a: 4). In Gamson's investigation of political talk, people formulate frames via a "resource strategy" (1992a: 117-134), that is, after both media content and direct or quasi-direct (i.e., through friends) experience of societal issues. The resulting frames are organized according to a threefold model that includes injustice, agency, and identity components (1992a: 6-7). The injustice component has a moral connotation: its presence is signalled by the use of ideas of injustice and by the identification of targets of moral indignation. In so doing, the injustice component tends towards a "hot cognition," that is, it produces political talk via a highly emotional prism. The agency component refers to the possibility to alter or contrast given conditions, e.g., specific policies or governmental decisions. Through the agency component, frames define people as potential agents in the social and political domain. Finally, the identity component refers to the process of identifying a 'we' in opposition to some "they" with a strongly different connotation.

Hence, frames populate political consciousness in everyday life talk, generating political discourse in the non-official political domain. Frame components differently emerge in political discourse depending on how people draw on mediagenerated knowledge and on their own experience (Gamson 1992a, 1992b) within their cultural community and, possibly, within any specific ideological group (Van Dijk, 2002).

\subsection{Blogging Politics}

Frame analyses of political discourse in the non-official political domain have primarily investigated social movements' collective action frames ${ }^{i}$ and framing processes in people's conversations (Gamson, 1992a; 1992b) ${ }^{\mathrm{ii}}$. While an emerging literature is now drawing attention to public sphere processes and new forms of political engagement in online contexts - with specific focus on social media - the shaping of online political discourse via framing processes has so far been overlooked. In particular, the growing literature on blogs as loci for political debate (Adamic and Glance, 2005; Chang Woo-young and Park, 2012; Etling et al., 2010; Herring et al., 2005; Moe, 2011; Park and Kluver, 2009; Radsch, 2008; Rahimi, 2011; Zhuo, 2009) has so far little investigated the possible emergence of collective action frames that may indicate a potential for mobilization around specific societal issues.

Overall, research on blogs and blogospheres has shown that blogging eases the renegotiation of public and private discourse practices, where popular and unpopular topics differently spread from blog to blog in dynamics of concentration and isolation. Moreover, blog content often mingles with that on other web 2.0 sites and with 
mainstream media agendas, possibly affecting larger public sphere dynamics. In line with these considerations, this study considers bloggers as social agents who blur argumentations in support or against normative politics via the extensive use of personal narratives and cultural knowledge.

\subsubsection{Blogging Politics in Cuba}

By applying a framing approach, this study specifically focuses on political discourse emerging in Cuban blogs. Cuba makes an interesting case study for several reasons. First, since the 1959 Revolution, Cuba has been ruled by an authoritarian government, that has full control on all media content, the only exception being the US-funded radio and TV Martí's programs. Despite this authoritarian approach has extended to new ICT platforms - generating high obstacles for public access to the Internet -, according to official statistics Cubans have on average extremely high ICT skills (ITU, 2012), with this figure being linked to the high literacy rates in the country.

Second, the Cuban context, given its geopolitical history, is characterized by a unique cultural mixing. As Venegas states, Cuba "offers a case study in how new private and public selves, aided by digital media, can evolve from the ruins of both capitalist and socialist schemes" (2010: 6). In particular, the Internet was introduced to Cuba in 1996, a moment in which the country was fully immersed in the Period Especial or the "Special Period in Times of Peace". The Special Period was officially declared at the end of 1990, when the disappearance of the Soviet bloc led to the country's loss of Soviet trade and support. This period - officially still in place but particularly felt in the first ten years - defined the country economically, politically and culturally. The extreme economic downturn characterized by both the US economic embargo and the sudden loss of Russian subsidies left "memories of deprivation and hopelessness; hunger and heat; of wheeling and dealing; of dreams of a life elsewhere" (Hernandez-Reguant, 2009a: 1). The country looked for remedy via opening up to foreign investment and international tourism, reforming its socialist constitution. Given the initial wave of economic reform, many thought that political change would also unfold, leading Cuba towards the same transition happened in the ex Soviet bloc after 1989. However, when economic indicators started improving, the government renewed its authoritarian control on both private entrepreneurship and oppositional discourses. Finally, while the "embargo culture" (Venegas, 2010: 8) continued affecting Cubans' everyday life - and bolstering anti-US ideas - the new economic situation also eased cultural changes. Many Cubans emigrated, reinforcing the imaginary of a new cosmopolitan Cuban identity. At home, while "high" culture stressed on the separation between arts and politics, popular culture started using communist symbols for popular critique (Hernandez-Reguant, 2009a: 11-12), mixing them with Cuban traditions and folklore.

Finally, against this background, Cuban authorities limited the development of the Internet to specific public sectors, namely official institutions and state companies, while private citizens started looking for access through work, hotels, hospitals and black market (Price, 2011: 40). Despite obvious limitations, Cuban Internet use emerged in the 2000s (Hoffman, 2011) and, since 2007, the number of personal and collective blogs has kept mushrooming.

While the limited literature on the Cuban blogosphere has so far provided a general discussion of its development given structural restrictions (Henken, 2011; Hoffman, 2011; author removed, unpublished; Uxo, 2010), this paper will focus on framing processing emerging in Cuban blogs. The aim is that of 
exploring how common sense, ideological and personal knowledge mingle in online non-official political talk in contemporary Cuba.

\section{Data}

The study focuses on the content published on 62 blogs from 1 July 2011 through 30 June 2012. Blogs were selected from four blog platforms populating the Cuban blogosphere: Voces Cubanas, Havana Times, Bloggers Cuba, and La Joven Cuba. More specifically, blogs were sampled according to their ideological leaning. Voces Cubanas (http://vocescubanas.com/) - turned from digital magazine into blog platform in 2007 - focuses on the emergence of citizen journalism that could offer a critical approach to state authoritarianism (Henken 2011: 174). Bloggers from Voces Cubanas, with Yoani Sanchez at the forefront, are often addressed as "dissident" by state officials (Author removed, unpublished). Havana Times (http://www.havanatimes.org/) - founded in 2009 - states that its aim is to offer an alternative to official media. Its position is of critical support for the Revolution. While its bloggers are Cuba-based, its founder, expatriate Circles Robinson, runs it from Nicaragua (Henken 2011: 176). Bloggers Cuba

(http://bloggerscuba.wordpress.com/) - the first blog platform published with official state consent (Hoffman 2011: 22) - after a troubled few years became active in 2011. The most prominent blogger here is Elaine Diaz, a University of Havana Professor of Communication. La Joven Cuba (http://lajovencuba.wordpress.com/) is a collective blog founded in 2010 by three young professors of the University of Matanzas Osmany Sánchez, Harold Cárdenas Lema and Roberto G. Peralo. La Joven Cuba is openly in support of state policies.

All blogs from the four platforms were included in the sample, save for photographic blogs, those not active in the sample period, and those non accessible at the time of coding (i.e., July-December 2012). Two Spanish-speaking researchers coded all the posts published during the sample period (i.e., 2,787 posts of which 1,447 from Voces Cubanas, 664 from Havana Times, 335 from Bloggers Cuba, and 341 from La Joven Cuba) according to a pre-set codebook. The codebook was designed to collect data on general issues and specific topics discussed in each post. Codes were generated by drawing upon Etling et al.'s (2009) codebook and adjusted to the Cuban context. In particular, for this phase of data collection, the first coder identified issues and topics covered in each post and extracted all the excerpts relevant to each specific topic. The second coder carried out input versus output verification, that is, she checked the correspondence between coded data and codes' definitions (Franzosi, 2004: 78).

The present study specifically focuses on one of the general issues discussed in the blogs: the Revolution as a political process. This issue was chosen for its salience and its relevance to the political domain (Van Djik 1995: 25-29). Three of the specific topics coded in the blogs were central to the unfolding of the political discourse around this issue: history of the Revolution, personal narratives of the past, and revolutionary idols. A total of 159 posts across 34 blogs from the four platforms addressed these specific topics, namely, 101 posts from Voces Cubanas blogs, 27 posts from Havana Times blogs, 2 posts from Bloggers Cuba blogs and 29 posts from La Joven Cuba.. Gamson (1992a)'s threefold approach to framing was then used to analyse the relevant excerpts from these 159 posts. More specifically, qualitative textual analysis was used to identify injustice, agency, and identity framing components in the discussion of the Revolution as a political process, with the 
ultimate goal to investigate how political discourse unfolds in contemporary Cuban blogging.

\section{The Revolution and Beyond}

"Patria o muerte" (fatherland or death) was the motto closing all Fidel Castro's speeches from January 1959 onwards (Hernandez-Reguant 2009a: 3). The idea of fatherland, at least for the first thirty years of the Castro's leadership, was directly linked to that of a political community whose ideological landmarks came from the very essence of the 1959 "Revolution". Those landmarks derived from a specific view of state socialism, one that framed Cuban society as "built on democratic values of equality, community and participation as defined and limited within a Martí inspired and Marxist-Leninist ideology" (Venegas 2010: 69). With the post 1989 economic crisis and the initial transition towards economic reform, the meaning of both fatherland and socialism became more symbolic than literal. In particular, public discourse started framing Cuban society more as a cultural than a political community (Hernandez-Reguant 2009b: 69) and, via a process of discursive inclusion, for the first time it started including Cubans out of the country.

Public discourse on the Revolution - understood as an ongoing political process started in 1959 - has then undergone several discursive adjustments over the past five decades and certainly represents an important element of contemporary political discourse. The following three sections will specifically focus on the way in which Cuban bloggers from different ideological streams discuss the Revolution using injustice, agency, and identity framing.

\subsection{Injustice}

\section{Voces Cubanas Bloggers}

Around $66 \%$ of the posts from Voces Cubanas bloggers discussing the Revolution use ideas of injustice. In particular, different phases of the Cuban history starting from 1959 are associated to personal struggles to obtain basic goods. This side of the Revolution is described with indignation:

"[with the Special Period] people started to understand that in order to obtain those dollars, that later became CUC ${ }^{\text {iii }}$, they had to do the opposite of what they were doing earlier. Hence, prostitution reappeared to meet tourists' demand and the granny with cancer had to move to a corner of the living room because her bedroom (the only one with a window on the street) had to be rented ${ }^{\text {iv }}$." (Desde Aquí, 14/11/2011).

Often bloggers use the term "double morality" to explain how people adjust their public behaviour to meet state policies and avoid sanctions:

"There were demonstrations of double morality: lies to save one's job, lies to have the rights to go on a little trip, lies to be able to rejoin relatives and friends" (Por el ojo de la aguja, 09/05/2012).

As evident from the quotes above, poverty is a central element in the discussion of the Revolution and its outcomes. Poverty takes different aspects in different periods, but 
an ironic account from Generacion $\mathrm{Y}$ can be used as representative of several others from Voces Cubanas bloggers:

"My only shoes had broken, those I had inherited from a friend when they already had huge holes in the soles. With them, I learned to walk rubbing the floor to hide the holes, but there was little I could do during the classes of Military Preparation. There, I had to lie down and crawl on the ground that - fictionally - was under enemy fire. And then I was under the fire, not of imperialism but of the jokes and cruel fun of those who had better shoes" (Generacion Y, 13/07/2011)

Not only moral indignation permeates narratives of people who lie to state control and hate and spy on one another to obtain minimal benefits from state officials. Moral indignation is also used to blame directly the state for its repressive take on educational, religious, political matters and sexual orientation:

"We were a generation whose eyes were covered at birth to dictate us the way to reason and erase our dreams, because they told us that the light would have blinded us. Our mothers stood injustice for fear and to protect us, because they knew that the worst had yet to come" (Los Hijos que nadie quiso, 19/08/2011).

Moreover, the Castros' governments are blamed of bolstering hatred within the Cuban population:

"I remember crowds who, more than 30 years ago attacked and insulted whoever tried to emigrate $[\ldots]$. Those were the most offensive and hateful images that I can remember in all my life, organized by the Cuban government. [...] To boost the vulgarity of the crowds has been one of the most successful methods of control used by the dictatorship" (Sin Evasion, 02/12/2011).

All the fragments so far reported are also representative of the sense of immutability that leaks from Voces Cubanas blogs. Evaluative statements showing acute indignation together with narratives of poverty and repression are all characterized by a fourth element that marks the injustice framing of these posts: an element of general resignation. These bloggers frame Cubans as tired by a long lasting situation and lacking any sort of agency to escape it:

"I worked and sacrificed for a better future that has never come and will never come." (Por el ojo de la aguja, 10/08/2011)

"Times do not change on this island." (Generacion Y, 07/09/2011)

"The worst is that on the faces of the inhabitants there is a mark of forgotten, past glory turned into salt." (Generacion Y, 19/04/2012)

The injustice component in Voces Cubanas' framing of the Revolution touches the different phases of the Castros' leadership, from the first thirty years of pure state socialism, to the harsh times of the Special Period when economic reform changed the 
original aspect of socialism in the country, and on to the current situation marked by the reforms brought by Raul Castro since 2008. There is a feeling of general rejection of the social changes that have affected civic life, with people being forced to struggle, lie and fight with one another to get basic goods and being controlled in different aspects of their private life. In fact, strong and direct criticism targets every aspect of state control. Injustice also lies in the widespread acceptance of the situation, where a tired population is framed as unable to react to see its basic rights respected.

\section{Havana Times Bloggers}

Similarly to Voces Cubanas, around $67 \%$ of the posts from Havana Times dealing with the Revolution draw upon an injustice component. The arguments used are also very similar, ranging from increasing poverty to political repression, on to the sense of "failed promises" following the initial years of the Revolution. However, while Voces Cubanas blogs express double indignation - directed at both state action and the changes affecting Cubans' civic life - here the attention is almost uniquely drawn to personal narratives and evaluative statements of state control, oppression and totalitarianism. The target of moral condemnation is then almost exclusively state action.

"To me the Cuban Revolution is a historical event definitely dried out, as the result more of the incapacity of those who were then young - today old - leaders to keep their promises than of the US embargo." (Alfredo Fernandez, 07/03/2012).

The blame is uniquely on Cuban leaders. Not only Havana Times bloggers generally discuss the failure of the Revolution as a process, they also report on specific phases and events that marked this failure. The "Zafra del 70", is an example:

"It was a colossal mistake that left the economy of the country weaker than before. And the most tragic was that we could not reach the planned quota." (Osmel Almaguer, 31/10/2011).

Economy a part, state control on private life is also widely discussed via examples taken from the history of the Revolution. Prieto, for instance, discusses the UMAP:

"Military Units of Support for the Production, a type of forced work camps that existed in Cuba for a few years in the 60s, with the alleged aim to "eliminate social scourges". They hosted homosexuals, Christians, rockers, hippies, vanguard writers; all strange people and future members of the hierarchy of the Catholic Church and the Movimiento de la Nueva Trova". (Dmitri Prieto, 25/062012)

In sum, Havana Times bloggers use explicit moral condemnation assigning the causes of injustice exclusively to the unfolding of the Revolution as directed by its leaders. Individual citizens participate in both narratives and evaluative statements but they always play the role of victims of the events, with no stress being put on any form of 
individual agency. One could say that the moral complexity of the issue is here eased by the explicit identification of a unique and undisputed target of blame.

\section{La Joven Cuba Bloggers}

Just over half of the posts from La Joven Cuba discussing the Revolution draw upon an injustice component. Ideas of injustice here have little in common with the arguments seen in the previous blogs as La Joven Cuba bloggers primarily express moral indignation in recounting what characterised Cuba before the Revolution.

"These are not the times when 9 or 10 years old children had to leave home to learn something or when, aged 14, they managed to feed other kids. Those, the great majority of humble families, lived and survived capitalism; for this reason they valued and defended with all means the rising Revolution" (La Joven Cuba, 31/01/2012)

"It is not in today's Cuba but in that before 1959 that inequalities and the lack of a future become evident" (La Joven Cuba, 07/06/2012)

One could say that La Joven Cuba writing follows a revolutionary rhetoric, still perfectly in line with the original values marking the foundation of the Castro's government in 1959. In fact, the two extracts above use traditional anti-capitalist claims and describe the Revolution as a bottom-up struggle for people's equality. However, among La Joven Cuba's posts one can also find a few more critical claims that, albeit not questioning the aims of the Revolution, condemn past policies and approaches to private life, in particular censorship on western music in the $60 \mathrm{~s}$ :

"All this was responsibility of those who saw symptoms of "ideological diversionism" in those who spoke English and had long hair. In the end, these censors were counterrevolutionaries or at least antirevolutionaries." (La Joven Cuba, 06/02/2012)

Most posts advance that what was wrong in the past fifty years was wrong because not in line with the original values of the Revolution, with the result of legitimising traditional revolutionary values.

Finally, moral indignation only finds a contemporary target when it addresses the lack of political engagement of contemporary Cuban youth as opposed to past revolutionary leaders:

"What would Jose Antonio or Mella say if they saw this inertia? Were their death and life of battle devoted to this? Are we so arrogant to believe that we live in a perfect system that does not need the explosion of its student' vanguard to improve it?" (La Joven Cuba, 22/06/2012)

La Joven Cuba definitely draws upon a socialist rhetoric, explicitly using arguments of injustice aligned with the traditional values of the Cuban Revolution. Instances of a critical approach do emerge in reflective accounts of past forms of censorship on popular culture and sexual orientation but moral indignation here is again functional to legitimise the very essence of the Revolution.

\subsection{Agency}




\section{Voces Cubanas Bloggers}

Among Voces Cubanas posts on the Revolution, less than 10\% use an agency component. In fact, the social dynamics and political structures described via the injustice component discourage any sense of agency and induce the expression of collective helplessness. Voices of potential agency are extremely limited and tend to centre on a private rather than a collective sphere of action. For instance, Lilianne Ruiz writes in relation to her young daughter at school:

"I won't allow them to use my daughter in their political campaigns. [...] I can't condemn my daughter to be an outcast like me." (Lilianne Ruiz, 05/12/2011)

The rare accounts of collective agency primarily refer to the 90s when the first critical graffiti appeared on the walls of La Havana, together with the first and limited, oppositional voices in the public arena.

"It is right to admit that the oppositional action at the beginning of the 90 s of the past century had the responsibility to break the myth of the political "unanimity" in Cuba and forced the government to admit the existence of sectors opposed to the system." (Sin Evasion, $18 / 07 / 2011)$

Generally speaking, these elements of agency deliver more a sense of quiescence than one of action. They indeed provide evidence of a will for change but are far from generating a sense of potential for collective agency.

\section{Havana Times Bloggers}

Almost $15 \%$ of Havana Times posts dealing with the Revolution use an agency component. As in Voces Cubanas, the potential for agency expressed in these posts is very limited and often expressed through the acknowledgement that there is no potential at all. For instance, Osmel Almaguer writes:

"These are vices of a socialist society devastated by the Special Period. I do not have a solution. I can't imagine a change that could fix the majority of these problems" (Osmel Almaguer, 13/02/2012)

Overall, the agency component in Havana Times posts on the Revolution is used to express the absence of potential for collective action in a way that is even more dramatic than in Voces Cubanas blogs.

\section{La Joven Cuba Bloggers}

Close to $28 \%$ of the posts from La Joven Cuba advance ideas of agency when discussing the Revolution. The framing of potential for future action here is totally different from that scantily present in Voces Cubanas and Havana Times. In fact, as in the case of the injustice component, the expression of collective agency aligns with the socialist rhetoric and stands in defence of the Revolution: 
"We have to involve young people more in the revolutionary process, talk much with them, make them feel protagonist and realise that their voice is important". (La Joven Cuba, 31/01/2012).

"We are the basis of this society and we must use our revolutionary being to guide us in the attempt to build a better future" (La Joven Cuba, 2206 2012).

Social agency is here driven by a moral obligation to the Cuban community, seemingly recalling the notion of fatherland so often mentioned in the Castro's rhetoric of the nation:

"We still have to create an autochthonous Marxist model, under enemy fire and living together with many who, thinking to create a better world, hijack it with their ignorance, while others do the same for opportunism". (La Joven Cuba, 27/09/2011).

In La Joven Cuba, agency is represented as an indispensable duty, primarily driven by anti-capitalist and collectivist values. The level of the discussion around social agency remains almost entirely abstract, anchored to the traditional landmarks of Cuban socialist rhetoric.

\subsection{Identity}

\section{Voces Cubanas Bloggers}

Identity, like injustice, is a dominant framing component in Voces Cubanas discussions on the Revolution as $66 \%$ of the relevant posts use ideas of identity. The identity framing provided by these posts is mainly adversarial, that is, it is functional to draw a dividing line between a "we" - the common people - and a "they" - mainly political leaders and party officials. In fact, identity is built via the identification of social groups with opposing features, e.g., those who have (i.e., politicians) and those who haven't (i.e., the people), revolutionaries and non/anti revolutionaries, those who stay in Cuba and those who emigrate; and contrasting ideological elements, e.g., socialist values and bourgeoisie values, religion and radical atheism.

Adversarial framing is often generated by addressing very specific targets as responsible of the economic decline of the country:

"Due to the totalitarian will of Fidel Castro who, for more than fifty years, considered everything as his own property [...], the last piece of Cuban patrimony that could survive is housing" (Los Hijos que nadia quiso, $15 / 11 / 2011$ )

"Where were our leaders who did not realise that everything was quickly deteriorating?” (Por el ojo de la aguja, 20/07/2011)

"The same fundamentalist power that has led us to destruction, that after fifty years of catastrophic direction has reduced our sugar production to less than 45 plant sites, that is, one and a half million tons, has then turned us into sugar importers. They left us without sugar and without a country. Is this surrealism?" (Criollo liberal, 17/04/2012). 
But again, as discussed earlier in relation to injustice framing, the downfalls are not only economic as in Voces Cubanas posts what "they" have done has led to changes in what "we" have become:

"I am worried about the future. Either you are an outcast, or a supporter of the government or you pretend you are" (Lillianne Ruiz, 05/12/2011).

Overall, identity is a strong component of Voces Cubanas framing and it strictly intertwines with ideas of injustice. Identity is functional to both express social divides and identify those specific targets of blame for which much injustice is affecting the society. Most importantly, the targets of adversarial framing are specific actors (i.e., political leaders: Fidel Castro, Raul Castro, Party officials) rather than abstractions (e.g., poverty, frustration), indicating potential for the emergence of collective action framing (Gamson 1992a: 85).

\section{Havana Times Bloggers}

Havana Times Bloggers use ideas of identity in almost half of their posts on the Revolution. The demarcation between "we" and "they" is very similar to that in Voces Cubanas writing:

"This is the situation in which Cubans live today, mostly due to the permanence in power of a generation who self-proclaimed, for more than five decades, as the only one able to lead the country" (Alfredo Fernandez, 07/03/2012).

As evident, political leaders are still target of blame while the population is victim of injustice. It is particularly interesting to see how Cubans' identity in the 60 s is framed as entirely crafted around a Soviet cultural model:

"there was no house without a Matrioska (dolls from Russian folklore) or a teddy bear Micha (logo of the 1980 Olympic Games in Moscow). People now over 35 y.o. have used a watch labelled Poljot, Vostok o Raketa, had to study Russian at school or listened to the lessons on the radio or TV." (Dariela Aquique, 28/08/2011).

It is exactly the use of personal narratives to describe identity changes in the Cuban population that makes Havana Times adversarial framing particularly interesting. Potential for collective action is less strong here than that in Voces Cubanas writing but the expression of cultural shifts due to political and economic changes, provides a powerful account of identity transitions in the Cuban society.

\section{Bloggers Cuba Bloggers}

Bloggers Cuba writing only devotes two posts to the Revolution where it provides a channel of identification via the glorification of traditional revolutionary idols:

"In the new sceneries and challenges that pushed the construction of a new society, Che understood that the fundamental element of the 
revolutionary work was the ideal of the New Man, and he embraced the ideals of Antonio Guiteras ${ }^{\mathrm{vi}}$ " (Bubusopia, 25/09/2011).

The use of Cuban heroes to frame identity can be further interpreted by looking at La Joven Cuba writing.

\section{La Joven Cuba Bloggers}

Slightly more than half of La Joven Cuba posts on the Revolution use an identity component. Similarly to Bloggers Cuba, revolutionary idols - especially Che Guevara - are here used as models for identification:

"The paradigmatic figure of Ernesto Guevara de la Serna is today more recurrent than ever. This Argentinean Cuban, or better this Argentinean of the world, for his example, sacrifice and pain, is guide and reason, energy and will for our land "from Rio Bravo to Patagonia". (La Joven Cuba, 09/10/2011).

" $\left[\right.$ Los Cinco $\left.{ }^{\mathrm{vii}}\right]$ have demonstrated that not only one has to believe in a cause; one needs to risk to defend it, as Che taught us" (La Joven Cuba, 05/07/2012)

The ideological rhetoric of La Joven Cuba reaches its climax with the identification of traditional and new revolutionary idols to be taken as exemplars. Actors here remain behavioural icons and participate in the reiteration of the traditional revolutionary vocabulary of action. In fact, La Joven Cuba writing shows here little evidence of a renewed discussion of identity values, still profoundly rooted in nostalgic accounts of an all-Cuban socialist discourse.

\section{Discussion}

In authoritarian contexts like Cuba, where media channels are either state-controlled or funded by foreign countries opposing the ruling government, mainstream media discourse can only provide a highly biased contribution to the development of political consciousness. An "integrated resource strategy" (Gamson, 1992a: 117-134) - where media discourse, personal experience and cultural knowledge all contribute to political cognition - is therefore limited in the sense that media discourse will be extremely polarised, either in total favour or in total opposition to state politics. A reason why blogospheres can become a viable platform for the expression of political consciousness in authoritarian contexts is exactly the fact that blogs often become diary-like productions where experiential and cultural knowledge, more than media discourse, highly influence the evaluation of content (Papacharissi, 2008: 238). In fact, an analysis of posts on civic life and societal issues allows one to measure the development of different framing processes broadly relevant to the political domain and to evaluate the extent to which such framing processes may hide deliberative quality of some sort.

This study used Gamson's theorisation of collective action frames to explore the way in which blogs from different ideological streams use ideas of injustice, agency and identity to discuss the Cuban Revolution as a political process. Findings show that the Cuban blogosphere overall hosts a varied discourse network that, although presenting strong elements of polarisation, offers an interesting mix of 
critical evaluations, personal commentaries and traditional socialist rhetoric that constitute the raw materials for an emerging online political debate. One of the most interesting features is that this particular mix varies depending on the ideological leaning of the bloggers.

Bloggers from the critical side of the political continuum heavily draw upon personal narratives. They use an injustice component to express moral indignation against governmental policies and state control via accounts of personal struggles. Voces Cubanas bloggers in particular express double indignation, i.e., at both state action and Cubans' lack of reaction. If the injustice component in this writing is very strong, elements of agency, while providing evidence of a will for change, are far from showing potential for collective action. In fact, the second target of indignation in Voces Cubanas posts, i.e., people's inaction, both permeates ideas of non-agency and contributes to an identity component. Identity is also built via a strong adversarial framing where the targets of blame are extremely concrete (i.e., political leaders).

More state-aligned bloggers, when discussing the Revolution, draw upon the Cuban cultural background of the past five decades more than on personal narratives. In terms of injustice, they broadly portray the year 1959 as the watershed for the transition between injustice and justice in Cuban history. In fact, their framing of social agency also remains almost entirely abstract, mainly grounded in the discussion of anti-capitalist and collectivist values. Identity is built around the iconisation of traditional revolutionary idols (e.g., Che Guevara) and the identification of contemporary ones (e.g., Los Cinco).

Overall, data show that political discourse in Cuban blogs grows around an often-unbalanced mix of experiential knowledge and traditional socialist rhetoric. On one hand, experiential knowledge - mainly used by critical bloggers - draws upon proximity issues, that is, cognitive elements that are salient to everyday life. On the other hand, traditional rhetoric - exclusively employed by state sympathisers resonates with the Cuban political culture of the past fifty years. While these elements characterise the emergence of political consciousness and political debate, data show little evidence of potential for collective action. On one side, critical bloggers produce strong injustice and identity components with emphasis on adversarial framing but their writing entirely lacks expression of agency, hence deliberative strength. On the other side, state-aligned bloggers mainly construct meaning on the basis of abstract elements, with very limited efforts in expressing action potential via any frame components.

\section{References}

Adamic L and Glance N (2005) The Political Blogosphere and the 2004 U.S. Election: Divided They Blog. Proceedings of the 3rd international workshop on Link discovery, 36-43.

Bateson G (1972) A Theory of Play and Fantasy. In: Bateson G (ed) Steps to an Ecology of Mind. Philadelphia: Intext.

Benford RD (1993a) Frame disputes within the nuclear disarmament movement. Social Forces 71: 677-701.

Benford RD (1993b) "You could be the hundredth monkey:' collective action frames and vocabularies of motive within the nuclear disarmament movement. Sociological Quarterly 34: 195-216.

Benford RD (1997) An insider's critique of the social movement framing perspective. Sociological Inquiry 67: 409-430. 
Benford RD and Snow DA (2000) Framing processes and social movements: an overview and assessment. Annual Review of Sociology 26: 611-639.

Etling B, Kelly J, Faris R and Palfrey J (2010) Mapping the Arabic blogosphere: politics and dissent online. New Media Society 12: 1225-1243.

Fairclough I and Fairclough N (2012) Political Discourse Analysis: A Method for Advanced Students. Oxon: Routledge.

Author removed What's in a Text? Answers from Frame Analysis and Rhetoric for Measuring Meaning Systems and Argumentative Structure. Unpublished manuscript. Press.

Gamson WA (1992a) Talking Politics. New York: Cambridge University

Gamson WA (1992b) The social psychology of collective action. In: Morris AD and Mueller CM (eds) Frontiers in Social Movement Theory. Yale University Press, New Haven, CT, 53-76.

Giugni M (1998) Was it Worth the Effort? The Outcomes and Consequences of Social Movements Annual Review of Sociology 98:371-93.

Giugni M (2012) 'The Outcomes of the Occupy Movement: Which Lessons Can We Draw from the Social Movement Literature?' Mobilizing Ideas. Available at: http://mobilizingideas.wordpress.com/2012/01/20/the-outcomes-of-the-occupymovement-whichlessons-can-we-draw-from-the-social-movement-literature/ (consulted June 2013).

Goffman E (1974) Frame Analysis: An Essay on the Organization of Experience. New York: Harper Colophon.

Halliday MAK and Matthiessen CMIM (2004) An Introduction to Functional Grammar, 3rd ed. London: Edward Arnold.

Henken T (2011) A Bloggers' Polemic: Debating Independent Cuban Blogger Projects in a Polarized Political Context. Proceedings of the Twenty-First Annual Meeting Association for the Study of the Cuban Economy (ASCE). Miami, Florida August 4-6, 2011. URL (consulted June 2013): http://www.ascecuba.org/publications/proceedings/volume21/pdfs/henken.pdf.

Hernandez-Reguant A (2009a) Writing the Special Period: An Introduction. In: Hernandez-Reguant A (ed) Cuba in the Special Period. Culture and Ideology in the 1990s. New York: Palgrave Macmillan, 1-18.

Hernandez-Reguant A (2009b) Multicubanidad. In Hernandez-Reguant A (ed.) Cuba in the Special Period. Culture and Ideology in the 1990s. New York: Palgrave Macmillan, pp. 69-88.

Herring SC, Kouper, I, Paolillo, JC, Scheidt, LA, Tyworth M (2005) Conversations in the Blogosphere: An Analysis "From the Bottom Up". Proceedings of the Thirty-Eighth Hawai'i International Conference on System Sciences (HICSS38). Los Alamitos: IEEE Press.

Hoffman B (2011) Civil society 2.0? How the internet changes state society relations in authoritarian regimes: the case of Cuba. GIGA working papers, No. 156. URL (consulted June 2013): http://hdl.handle.net/10419/47847.

Meyer D and Whittier N (1994) Social Movement Spillover Social Problems 41(2): 277-298.

Moe H (2011) Mapping the Norwegian Blogosphere: Methodological Challenges in Internationalizing. Social Science Computer Review 29(3): 313-326.

Papacharissi Z (2008) The virtual sphere 2.0. The Internet, the public sphere, and beyond. In: Chadwick A and Howard PN (eds.) Routledge Handbook of Internet Politics. London: Routledge, pp. 230-245. 
Park HW and Kluver R (2009) Affiliation in political blogs in South Korea: Comparing online and offline social networks. In: Goggin G. and McLelland M (eds) Internationalizing Internet studies. New York, NY: Routledge, 252-265.

Price R (2011) New Media's New Literature. Review: Literature and Arts of the Americas 44(1): 39-46.

Radsch C (2008) Core to Commonplace: The evolution of Egypt's blogosphere. Arab Media and Society 6. URL (consulted June 2013): http://www.arabmediasociety.com/?article $=692$

Rahimi B (2011) The Agonistic Social Media: Cyberspace in the Formation of Dissent and Consolidation of State Power in Postelection Iran. The Communication Review 14(3): 158-178.

Rochon TR (1994) Culture Moves. Ideas, Activism and Changing Values. Princeton: Princeton University Press.

Snow D (2004) Framing processes, ideology, and discursive fields. In: Snow D, Soule SA, Kriesi H. (Eds.), The Blackwell Companion to Social Movements. Blackwell, Malden, MA, pp. 380-412.

Snow DA and Benford RD (1988) Ideology, frame resonance, and participant mobilization. International Social Movement Research 1: 197-218.

Snow DA and Benford RD (1992) Master frames and cycles of protest. In: Morris A, Mueller, CM (eds) Frontiers in Social Movement Theory. Yale University Press, New Haven, CT, 133-156.

Snow DA and Byrd SC (2007) Ideology, framing processes, and Islamic terrorist movements. Mobilization 12: 119-136.

Snow DA, Rochford BE, Worden S and Benford RD (1986) Frame alignment processes, micromobilization, and movement participation. American Sociological Review 51, 464-481.

Snow DA, Vliegenthart R, Corigall-Brown C (2007) Framing the French riots: a comparative study of frame variation. Social Forces 86: 385-415.

Uxo C (2010) Internet Politics in Cuba Telecommunications. Journal of Australia 60(1): 12.1-12.16.

Van Dijk L (1997) What is Political Discourse Analysis? In: Blommaert J and Bulcaen C (eds) Political linguistics. Amsterdam: Benjamins, 11-52.

Van Dijk L (2002) Political discourse and political cognition In: Chilton PA and Schäffner C (eds), Politics as Text and Talk. Analytical approaches to political discourse. Amsterdam: Benjamin, 204-236.

Venegas C (2010) New Directions in International Studies: Digital Dilemmas: The State, The Individual, and Digital Media in Cuba. New Brunswick: Rutgers University Press.

Author removed (2010)

Author removed

Woo-young C and Park HW (2012) The Network Structure of the Korean Blogosphere. Journal of Computer-Mediated Communication 17: 216-230. URL (consulted June 2013): http://onlinelibrary.wiley.com/doi/10.1111/j.10836101.2011.01567.x/full

Zhuo X (2009) The political blogosphere in China: A content analysis of the blogs regarding. New Media Society 11: 1003-1022.

\section{Endnotes}


${ }^{\text {i }}$ For a review of empirical studies on social movements' framing, see Author removed 2010 : Appendix A.

${ }^{\text {ii }}$ Media frames, since emerging directly from media content, are here considered as a separate type of frames.

iii The CUC (Cuban convertible peso) is an official currency introduced in Cuba in 1994 as an equivalent of the U.S. dollar. It is primarily used by tourists on the island.

${ }^{\text {iv }}$ All excerpts were translated in English by the author.

"The "Zafra de los diez miliones" indicates the 1970 government campaign to reach the production of ten million tons of sugar by the end of the year. The target was never achieved. ${ }^{\mathrm{vi}}$ Antonio Guiteras was a Cuban politician in the 1930s.

vii "Los Cinco" (The five) are five Cuban intelligence agents convicted in the US in 1998 for conspiracy to commit espionage. 